\title{
ANALISIS PETA STRUKTUR DOMAIN KEDALAMAN DENGAN INTERPRETASI SEISMIK 3D DALAM STUDI PENGEMBANGAN LAPANGAN “KAPRASIDA", BLOK "PATALA", ENERGI MEGA PERSADA TBK
}

\author{
Fahmi Aulia Rahman, Ayi Syaeful Bahri, Juan Pandu G. N. R \\ Jurusan Teknik Geofisika, FTSP Institut Teknologi Sepuluh Nopember \\ e-mail: fahmiar96@gmail.com
}

\begin{abstract}
Abstrak. Pengembangan lapangan migas masih sangat digencarkan, khususnya pada Lapangan "Kaprasida". Pada lapangan ini dilakukan studi pengembangan terhadap reservoar sekunder, yaitu pada Formasi Transisi, Upper Menggala, dan Lower Menggala. Reservoar sekunder masih menyimpan beberapa struktur jebakan hidrokarbon yang perlu analisis lebih dalam. Oleh karena itu, pada lapangan ini dilakukan proses reinterpretasi terhadap patahan dan lapisan tersebut, sehingga menghasilkan peta struktur domain waktu dan domain kedalaman. Maksud dari penelitian ini adalah untuk melakukan reinterpretasi yang menghasilkan peta struktur domain waktu dan kedalaman, sehingga dapat melakukan analisis pada peta struktur. Setelah dilakukan analisis pada peta struktur domain kedalaman ketiga lapisan, didapatkan beberapa zona target berupa beberapa struktur antiklin. Zonasi struktur antiklin terdapat pada wilayah barat TG2, selatan TG2, timur TG2, barat TG4, dan utara TG1. Dari hasil penelitian ini diharapkan dapat memberikan struktur jebakan hidrokarbon baru untuk kegiatan pengembangan Lapangan "Kaprasida".
\end{abstract}

Kata Kunci: pengembangan lapangan migas; interpretasi seismik; struktur jebakan hidrokarbon

\begin{abstract}
Oil and gas field development is still on progress, especially in "Kaprasida" field. Research development has been done in this field, focusing on its secondary reservoir, which are Transition Formation, Upper Menggala Formation, and Lower Menggala Formation. On the secondary reservoirs, there are some hydrocarbon trap that need more deeper analysis. Therefore, reinterpretation of fault and horizon has also been done that resulting time structure map and depth structure map. The aim of this research is to reinterpret data to get time structure map and depth structure map, then the structural analysis of the depth map. After the structural analysis of three horizon depth map, there are some target zones as an anticline structure. There are an anticline structure zones at west of TG2 area, south of TG2 area, east of TG2 area, west of TG4 area, and north of TG1 area. The result of this research is hopefully to give a new hydrocarbon trap structure to develop "Kaprasida" Field.
\end{abstract}

Keywords: oil and gas field development; seismic interpretation; hydrocarbon structural trap

\section{PENDAHULUAN}

Kegiatan pengembangan lapangan migas masih digencarkan, oleh sebab itu kegiatan reinterpretasi seismik diperlukan untuk menemukan beberapa potensi migas baru. Kegiatan reinterpretasi seismik meliputi beberapa pekerjaan, yaitu pengikatan data sumur terhadap data seismik, interpretasi patahan, interpretasi lapisan, pemetaan struktur domain waktu, konversi domain waktu ke kedalaman, dan analisis struktur pada peta struktur domain kedalaman.

Kegiatan interpretasi seismik tidak hanya membutuhkan data seismik, melainkan data sumur dan studi geologi regional yang juga dibutuhkan. Peran data seismik dalam proses interpretasi adalah untuk memberikan resolusi lateral seluruh wilayah lapangan, sedangkan peran sumur adalah untuk memberikan resolusi vertikalnya. Peran studi geologi regional adalah sebagai dasar geologi lapangan yang mempengaruhi hasil dari proses interpretasi seismik.

Penelitian ini bertujuan untuk melakukan reinterpretasi seismik lapisan reservoar sekunder pada lapangan "Kaprasida" yang kemudian menghasilkan peta struktur domain waktu dan kedalaman. Selain itu, penelitian ini juga bertujuan untuk menganalisa zona struktur jebakan hidrokarbon yang terdapat pada lapisan Transisi, Upper Menggala, dan Lower Menggala. 


\section{TINJAUAN PUSTAKA}

\section{Geologi Regional}

Lapangan "Kaprasida" terletak pada wilayah daratan, Blok "Patala", Provinsi Riau, Sumatera. Lapangan ini dinyatakan discovery pada tahun 1986 dengan pengeboran sumur TG2-1. Pada pengeboran sumur TG2-1 ditemukan minyak pada formasi Sihapas dengan lima zona menarik. Kemudian dilakukan lagi pengeboran sumur TG1-1 dalam rangka eksplorasi pada tahun 1986 untuk mengetahui jalur migrasi minyak pada lapangan ini. Sampai saat ini masih dalam tahap pengembangan untuk jebakan minyak formasi selain Sihapas, hal ini disebabkan oleh formasi sihapas telah berproduksi minyak.

Setelah dilakukan studi pengembangan, dapat dikutip bahwa sumber hidrokarbon berasal dari Pematang brown shale pada lokasi Barat Daya lapangan "Kaprasida". Jalur migrasi batuan induk bergerak ke arah lapangan "Kaprasida" dengan arah Timur Laut dan mengisi beberapa struktur pada formasi Sihapas (reservoar primer) dan formasi Transisi - Menggala (reservoar sekunder).

PSC atau blok "Patala" terletak pada cekungan Sumatera Tengah, cekungan Sumatera Tengah sendiri memiliki setting cekungan busur belakang. Blok "Patala" sangat berhubungan dengan Barisan arc dan pergerakan lempeng India. Terdapat beberapa elemen tektonik pada blok "Patala" yaitu:

- Distribusi Graben Pematang

- Palung Bengkalis

- Graben Padang Utara
- Palung Melibur -TA

- Palung Rangsang

- Palung Merbau

- Palung Bengkalis Timur

- Palung Bengkalis Utara

- Dua Patahan Mayor

- Patahan Mengkapan - Lalang

- Patahan Padang

Sistem petroleum pada blok "Patala" terbagi menjadi berikut ini:

- Batuan Induk

Semua bukti yang tersedia menyatakan bahwa sekuen shale lacustrine pada formasi brown shale menjadi sumber hidrokarbon pada fase syn-rift di wilayah palung Bengkalis. Batuan induk lain yang menjadi potensi adalah shale dan coal pada formasi Sihapas.

- Reservoar

- Pasir marine pada formasi Telisa

- Pasir deltaik pada formasi Sihapas

- Pasir fluvial pada formasi Transisi

- Pasir fase Syn-rift pada formasi Menggala

- Pasir fase Syn-rift pada formasi Pematang

- Zona patahan pada sekitar basement

- Jebakan

- Jebakan yang terbentuk pada fase mayor tektonik berupa antiklin major dan patahan (four way and three way dip closure)

- Struktur low relief pada formasi Telisa

- Jebakan struktur pada fase Syn-rift

- Jebakan stratigrafi pada formasi Menggala dan Pematang

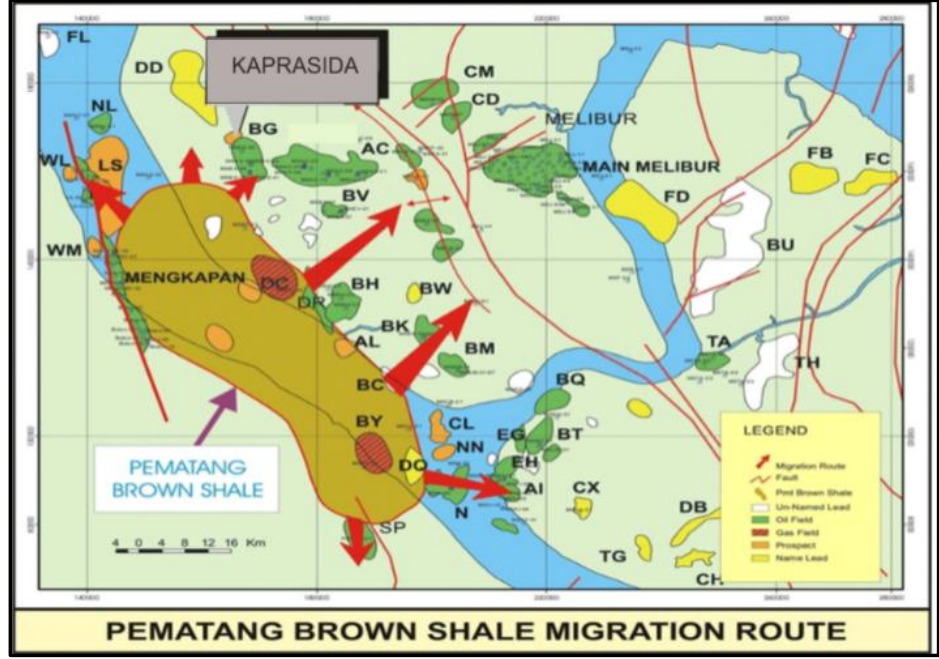

Gambar 1. Lokasi dan Jalur Migrasi pada Lapangan “Kaprasida” (EMP, 2008) 


\section{Pengikatan Data Sumur terhadap Data Seismik}

Pengikatan data sumur ke data seismik dilakukan untuk mengikat data sumur yang terdapat dalam domain kedalaman terhadap data seismik dalam domain waktu. Proses pengikatan data sumur terhadap data seismik dilakukan, agar horizon seismik dapat diletakkan pada posisi kedalaman yang sebenarnya. Data log yang digunakan adalah log sonic, log density dan checkshot untuk mendapatkan log impedansi atau koefisien refleksi. Proses ini dilakukan dengan membuat suatu seismogram sintetik yang dihasilkan dari konvolusi wavelet dengan deret koefisien refleksi. Trace seismogram sintetik yang didapat dikorelasikan dengan trace seismik sampai mendapatkan kecocokan atau kemiripan. Pada proses ini juga perlu diperhatikan adalah wiggle antara seismik dan seismogram sintetik-nya baik dari pola maupun besarnya wiggle tersebut. Pada proses ini melakukan stretch and squeez namun perlu diperhatikan interval TVD (True Vertical Depth) harus konsisten. Well seismic tie dilakukan, jika nilai korelasi yang dihasilkan mendekati angka satu dan diusahakan timeshift nol untuk memperoleh data ikat sumur-seismik yang maksimal.

\section{Interpretasi Patahan dan Lapisan}

Sesar atau patahan merupakan zona rekahan pada lapisan batuan yang telah mengalami pergeseran baik secara garis lurus maupun terputar, sehingga terjadi perpindahan antara bagian-bagian yang berhadapan. Pergeseran/perpindahan batuan tersebut terjadi di sepanjang suatu permukaan disebut bidang sesar (fault plane).

Sesar terjadi akibat tekanan yang tidak seimbang pada suatu lapisan batuan. Sebagaimana dijelaskan pada teori elastisitas, batuan tersebut akan mengalami deformasi, yang apabila melewati ambang batas kekuatan elastisitasnya batuan tersebut akan mengalami patahan/sesar.

Dalam pemahaman sederhana, sesar terdiri atas dua bagian non-vertikal yang disebut hangingwall dan footwall. Dari definisi, hanging-wall merupakan bagian sesar yang berada di atas bidang patahan. Sedangkan footwall merupakan bagian yang berada di bawah bidang sesar.

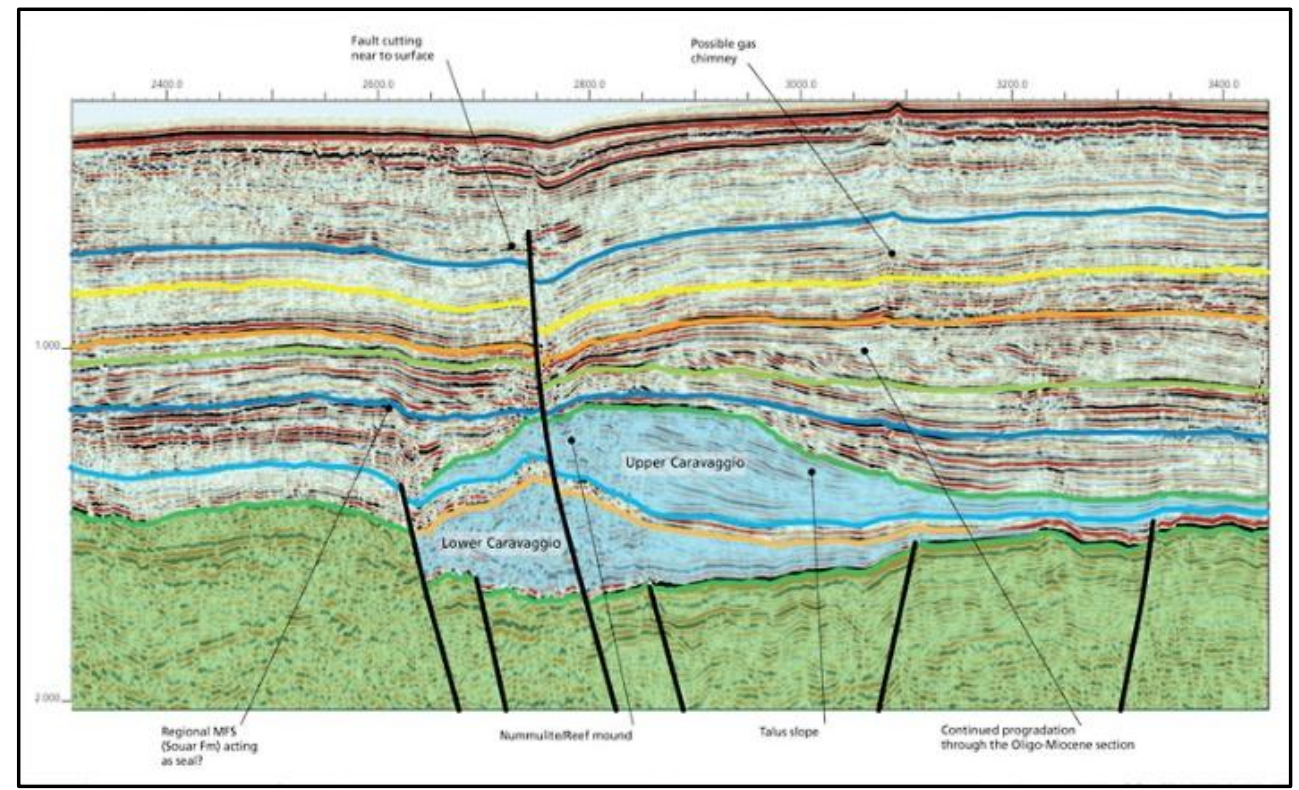

Gambar 2. Contoh Interpretasi Patahan dan Lapisan Pada Data Seismik (Heritage Oil, 2014).

Pada dasarnya Interpretasi horizon atau picking horizon dilakukan untuk membatasi asumsi formasi atau lapisan yang akan dipetakan menjadi peta struktur. Pada umumnya picking horizon dilakukan berdasarkan refleksi seismik yang tinggi dan kontinu, hal ini didasari asumsi bahwa setiap muka gelombang menandakan medium baru, maka akan menyebabkan kontras impedansi pada data 
seismik. Pada proses picking horizon dilakukan pembatasan berdasarkan medium dan umur dari lapisan tersebut. Alangkah baiknya ketika kita memiliki marker dari data sumur dan target lapisan yang akan dipetakan, kita dapat menarik lapisan dari marker tersebut.

\section{Time to Depth Conversion}

Time to depth conversion adalah proses perubahan domain pada data seismik yang semula berdomain waktu menjadi berdomain kedalaman. Dalam hal ini peta struktur seismik yang tadinya berdomain waktu (Time structure map) diubah menjadi berdomain kedalaman (Depth structure map). Proses ini sangat penting dilakukan mengingat masih ada perbedaan antara kedua domain ini yang dapat menimbulkan ambiguitas ketika diinterpretasi, Hal ini terjadi karena pada dasarnya kondisi aktual adalah berdomain kedalaman, sedangkan seismik memiliki domain waktu (Two-way time). Dalam proses ini terdapat beberapa metode yaitu metode kurva waktu dan kedalaman, metode kecepatan migrasi, metode tomografi kecepatan dan lainnya. Pada penelitian ini, digunakan metode kurva waktu kedalaman dalam konversi domain ini. Metode kurva waktu kedalaman dilakukan dengan cara mengasumsi hubungan waktu dan kedalaman dari data checkshot atau VSP. Dari hubungan tersebut didapatkan persamaan konversi yang cenderung linier atau polinomial. Setelah memasukan persamaan terhadap peta struktur waktu, dilakukan pengikatan peta terhadap marker top data sumur yang tersedia, sehingga menghasilkan peta residual tersebut.

\section{METODOLOGI PENELITIAN}

Penelitian ini membutuhkan beberapa perangkat keras dan lunak, sebagai berikut ini. Perangkat keras :

\section{- 1 Unit Mobile Workstation}

Perangkat lunak :

$$
\begin{array}{ll}
\text { - } & \text { Petrel } \\
\text { - } & \text { Seisee } \\
\text { - } & \text { Hampson Russell } \\
\text { - } & \text { Microsoft Office }
\end{array}
$$

Penelitian tugas akhir ini menggunakan beberapa data sebagai input seperti yang dijelaskan pada diagram alir di bawah, data tersebut memiliki spesifikasi sebagai berikut.

- Data Seismik 3D PSTM Wilayah Lapangan "Kaprasida"

o Inline $1380-1690$ (311)

o Xline 310-800 (491)

o $\quad$ Step $=1$

o $\quad X=196129,68$

o $Y=119087,64$

o Interval $=25$ Meter

o $\quad$ Time $=0$ s.d. -4000 TWT

- 11 Data Sumur, Checkshot, dan Tops Wilayah Lapangan "Kaprasida"

- Data Studi Geologi Regional Wilayah Lapangan "Kaprasida"

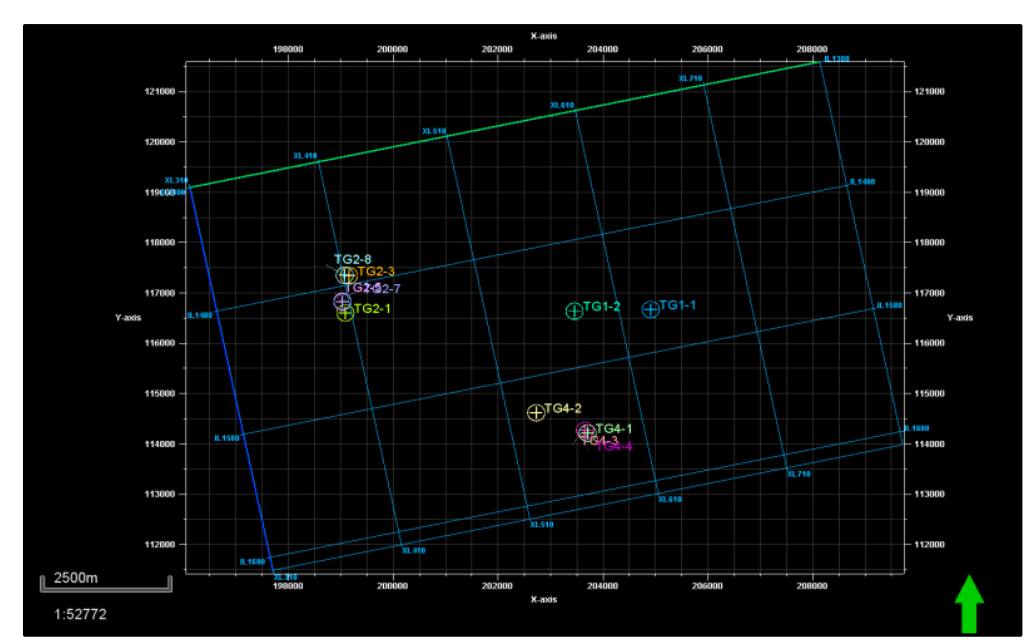

Gambar 3. Base Map Data Seismik dan Sumur Lapangan "Kaprasida”. 
Secara garis besar, metodologi penelitian ini digambarkan oleh diagram alir di bawah ini.

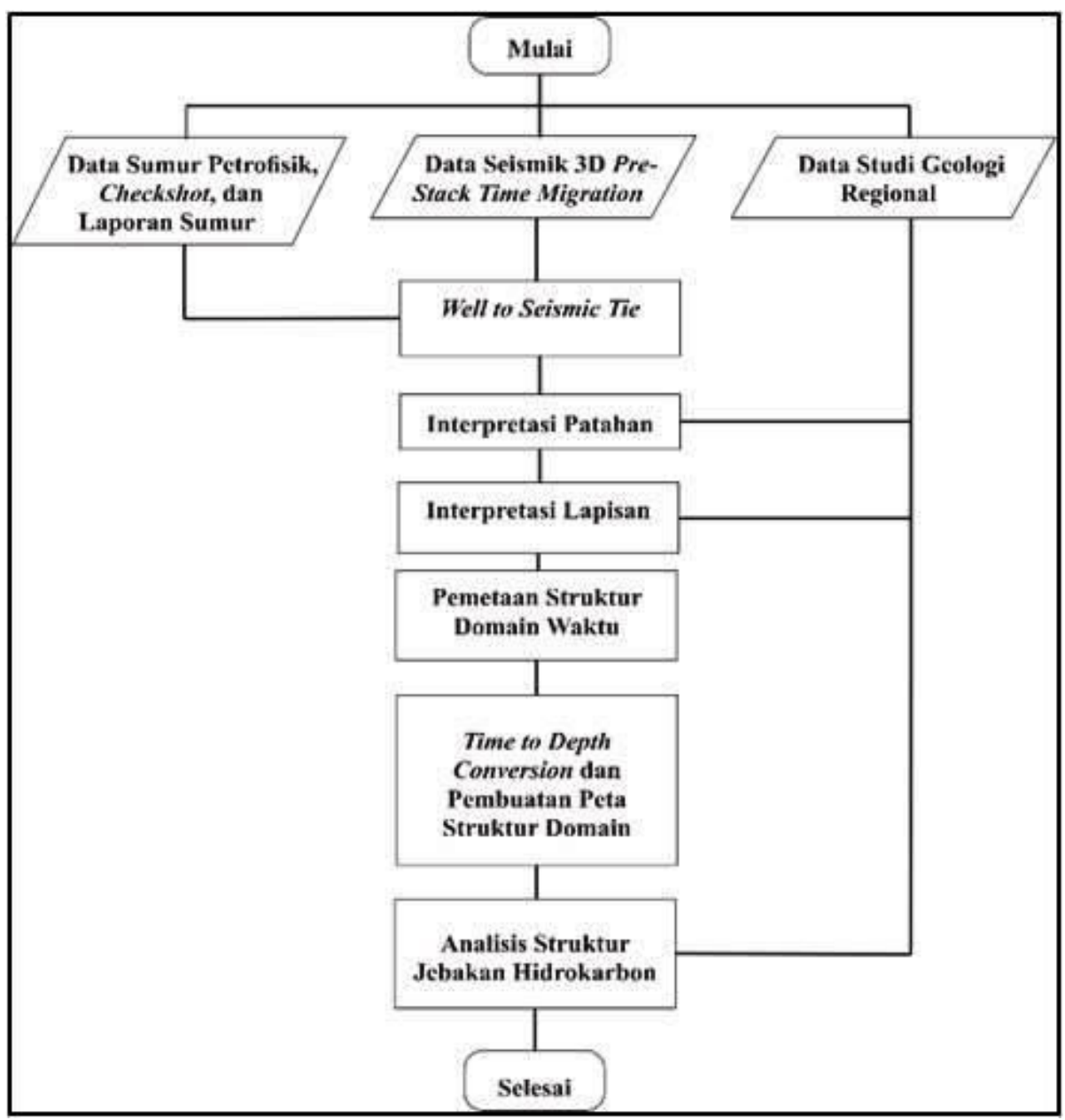

Gambar 4. Diagram Alir Penelitian untuk Analisis Struktur Jebakan Hidrokarbon.

Pengolahan data diawali dengan tahap pengikatan data sumur terhadap data seismik. Analisis dan proses pengikatan data sumur terhadap data seismik membutuhkan beberapa data sumur, yaitu data Log Sonik (Pwave), Log Densitas (RHOB), dan Checkshot. Tahap pertama adalah pembuatan seismogram sintetis yaitu dengan cara mengalikan Log sonik dengan Log Densitas. Hasil dari perkalian itu adalah Log Impedansi Akustik, kemudian diubah menjadi Log Koefisien refleksi (RC) dengan perbandingan beberapa lapisan. Setelah itu, Log RC dikonvolusikan dengan wavelet yang telah diuji sehingga menghasilkan seismogram sintetis. Tahap setelahnya adalah mengaplikasikan koreksi data
Checkshot yang kemudian siap dibandingkan dengan data seismik real time pada CDP yang mewakili lokasi sumur. Pada penelitian ini, proses pengikatan data sumur dengan seismik dilakukan dengan Perangkat lunak Hampson Russell.

Proses korelasi data sumur dengan data seismik membutuhkan wavelet yang merepresentasikan gelombang seismik tersebut dan juga ideal untuk korelasi, parameter penting adalah frekuensi wavelet. Demi mendapatkan wavelet ideal dilakukan ekstraksi wavelet dari seismik dan sumur, setelah itu didapatkan frekuensi ideal antara $23 \mathrm{~Hz}$ hingga $27 \mathrm{~Hz}$. Oleh sebab itu, dilakukan pembuatan wavelet ricker dengan frekuensi $25 \mathrm{~Hz}$. 


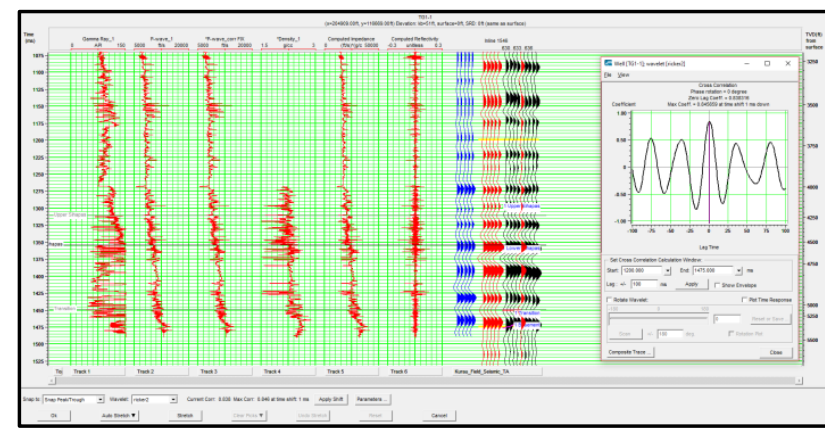

Gambar 5. Korelasi Data Sumur TG1-1 dengan Data Seismik.

Tabel 1. Nilai Korelasi Masing-Masing Sumur.

\begin{tabular}{|c|c|c|c|c|}
\hline No & $\begin{array}{c}\text { Nama } \\
\text { Sumur }\end{array}$ & $\begin{array}{c}\text { Jenis } \\
\text { Sumur }\end{array}$ & Checkshot & $\begin{array}{c}\text { Nilai } \\
\text { Korelasi }\end{array}$ \\
\hline 1 & TG1-1 & Vertikal & TG1-1 & 0,838 \\
\hline 2 & TG1-2 & Vertikal & TG1-2 & 0,806 \\
\hline 3 & TG2-1 & Vertikal & TG2-3 & 0,682 \\
\hline 4 & TG2-3 & Vertikal & TG2-3 & 0,684 \\
\hline 5 & TG2-5 & Deviasi & TG2-5 & 0,603 \\
\hline 6 & TG2-7 & Deviasi & TG2-3 & 0,706 \\
\hline 7 & TG2-8 & Deviasi & TG2-3 & 0,708 \\
\hline 8 & TG4-1 & Vertikal & TG4-1 & 0,607 \\
\hline 10 & TG4-2 & Vertikal & TG4-2 & 0,590 \\
\hline 11 & TG4-3 & Deviasi & TG4-1 & 0,632 \\
\hline
\end{tabular}

Interpretasi yang pertama dilakukan adalah interpretasi patahan. Hal ini dilakukan untuk mengetahui terlebih dahulu kondisi patahan pada wilayah interpretasi. Dalam kasus ini patahan bisa berperan sebagai dua hal, yaitu pembatas (kompartemen) atau jalur migrasi. Dengan menginterpretasi patahan terlebih dahulu, kita bisa lebih mudah menginterpretasi lapisan untuk memperlihatkan struktur jebakan Hidrokarbon. Dalam penelitian ini penulis menginterpretasikan patahan yang dianggap major. Berdasarkan studi geologi pada daerah ini, patahan major ditandai dengan arah relatif Utara - Selatan.

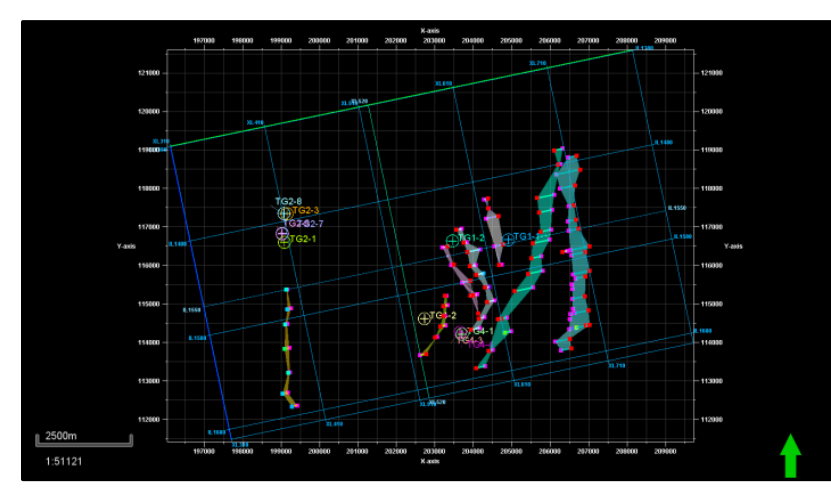

Gambar 6. Patahan Major yang Terletak pada Wilayah Studi.

Setelah melakukan interpretasi patahan, kemudian dilakukan interpretasi lapisan, pada dasarnya penelitian ini memiliki target sebanyak tiga lapisan, yaitu Transisi, Upper Menggala, dan Lower Menggala. Namun, penulis melakukan interpretasi lapisan sebanyak enam lapisan, tiga lapisan lainnya berfungsi sebagai referensi lapisan untuk memudahkan proses interpretasi, tiga lapisan lainnya adalah Upper Sihapas, Lower Sihapas, dan Basement. Interpretasi lapisan dilakukan dengan spasi tiap satu increment seismik. Interpretasi lapisan yang dilakukan harus menyesuaikan dengan logika geologi yang terjadi, sebelum melakukan interpretasi lapisan, seorang interpreter harus memahami proses pembentukan cekungan, pengisian cekungan, dan evolusi cekungan pada wilayah tersebut.

Pada dasarnya interpretasi lapisan dimulai dari lokasi tops sumur yang telah dikorelasikan dengan data seismik. Kemudian, berjalan tiap increment satu pada inline setelah dan sebelumnya. Interpretasi dimulai dengan lapisan Upper Sihapas, Lower Sihapas, dan Transisi, hal ini disebabkan karena pada ketiga lapisan ini dikelompokan pada fase pengisian sedimen masa tenang ( $\mathrm{Sag}$ ) sehingga lebih mudah diinterpretasikan karena memiliki pergerakan tektonik yang cenderung sedikit. Kemudian interpretasi patahan dilanjutkan pada lapisan Upper Menggala dan Lower Menggala, pada lapisan ini pergerakan tektonik memasuki fase 
inversi, sehingga masih dikategorikan pada fase tektonik aktif. Lapisan terakhir yang diinterpretasikan adalah Basement, lapisan ini ditandai dengan kecepatan lapisan yang lebih tinggi, karena merupakan lapisan yang sangat kompak.

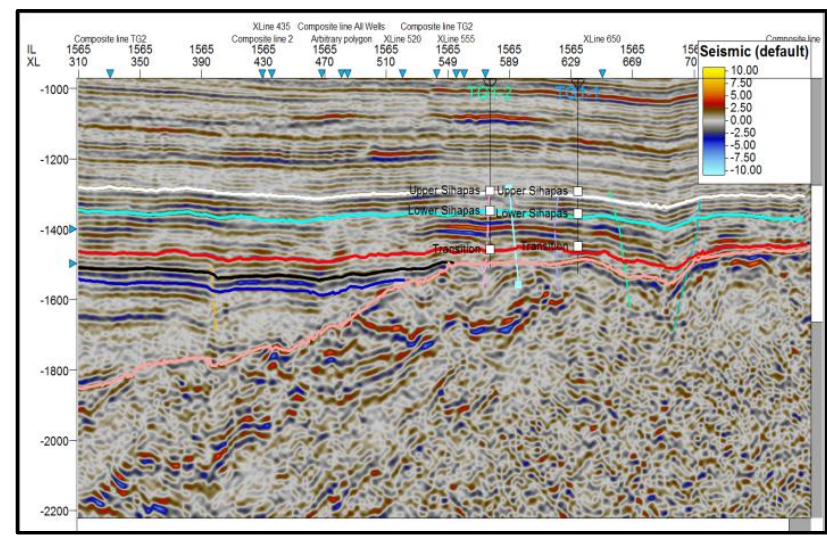

Gambar 7. Interpretasi Patahan dan Lapisan pada inline 1565.

Pemetaan struktur domain waktu dilakukan dengan menggunakan metode gridding untuk mendapatkan peta hasil interpolasi dan ekstrapolasi karena tidak semua lokasi dari lapangan "Kaprasida" memiliki data lapisan tersebut. Pada saat akuisisi seismik lapangan ini, spasi geophone sebesar 25 meter, maka sesungguhnya terdapat gap data.

Pada dasarnya metode gridding memiliki beberapa parameter untuk pemetaan, parameter utamanya adalah logaritma yang digunakan dan ukuran grid yang digunakan. Logaritma yang digunakan mempengaruhi hasil dari perhitungan interpolasi dan ekstrapolasi, untuk mendapatkan logaritma yang tepat, harus disesuaikan dengan tujuan utama pemetaan. Pada kasus ini tujuan pemetaan adalah untuk memetakan struktur lapisan, maka logaritma yang sesuai adalah konvergen (SCM E\&P, 2011). Parameter selanjutnya adalah ukuran grid yang digunakan, ukuran grid menjadi acuan bin pemetaan, asumsinya adalah semakin besar ukuran grid maka pemetaan menjadi tidak detil, namun tidak selalu bahwa ukuran grid kecil menjamin hasil pemetaan yang lebih baik. Oleh sebab itu, perlu dilakukan pengujian beberapa ukuran grid pada data untuk mendapatkan hasil pemetaan yang baik. Setelah dilakukan beberapa percobaan ukuran grid, didapatkan ukuran grid $50 \mathrm{x}$ 50 yang merepresentasikan struktur dengan baik pada lapisan Transisi, Upper Menggala, dan Lower Menggala.



Gambar 8. Hasil Pemetaan Struktur Domain Waktu Lapisan Transisi.

Time to depth conversion dalam suatu tahapan interpretasi seismik merupakan hal yang penting, hal ini dikarenakan domain seismik yang masih dalam domain waktu harus diubah menjadi domain kedalaman untuk merepresentasikan dalam kondisi sesungguhnya. Pada penelitian ini digunakan metode single function time to depth conversion. Metode single function adalah salah satu metode konversi domain kedalaman yang mengacu terhadap hubungan domain waktu dan kedalaman dari data checkshot tiap sumur yang tercakup dalam peta struktur (Abdullah, 2009). Pada penelitian ini terdapat beberapa tahap konversi domain kedalaman, yaitu yang pertama adalah mendapatkan persamaan regresi linier yang merepresentasikan hubungan domain waktu dengan kedalaman tiap sumur pada masing-masing formasi, selanjutnya adalah mengkalkulasikan persamaan tersebut terhadap peta struktur domain waktu, kemudian mencocokan peta hasil kalkulasi dengan tops data sumur tiap formasi.

Regresi linier dilakukan pada tiap lapisan yang ingin dikonversi. Tahap pertama adalah membatasi interval regresi, hal ini mengacu dari interval domain waktu (TWT) lapisan tersebut, kemudian dilakukan regresi terhadap kedua data tersebut. 
Berikut ini adalah persamaan regresi linier lapisan Transisi, Upper Menggala, dan Lower Menggala.

$$
\begin{aligned}
& Y=5,5942(X)+3115,3 \\
& Y=5,8271(X)+3455,2 \\
& Y=6,4109(X)+4348,6
\end{aligned}
$$



Gambar 9. Peta Struktur Domain Kedalaman Hasil Regresi Linier Lapisan Transisi.

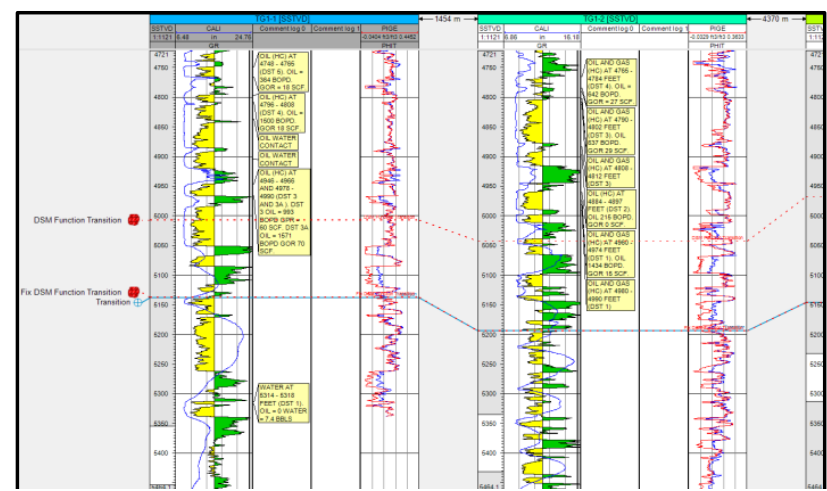

Gambar 10. Koreksi Residual Terhadap Tops Formasi Masing-Masing Lapisan dan Sumur.

Setelah dilakukan kalkulasi ketiga persamaan di atas pada peta struktur masing-masing lapisan, masih terdapat interval kedalaman yang belum akurat pada peta tersebut. Gambar 10 memperlihatkan perbedaan interval kedalaman peta hasil kalkulasi dengan tops pada data sumur sesungguhnya. Oleh karena itu, dilakukan pencocokan atau penarikan peta hasil kalkulasi terhadap tops tiap formasi dengan acuan data sumur. Koreksi tops sumur ini membutuhkan peta residual yang kemudian dikalkulasikan sehingga peta struktur kedalaman memiliki kedalaman yang sama dengan tops pada data sumur. Peta residual diperoleh dengan cara memasukan interval kedalaman lapisan pada setiap titik data sumur yang kemudian melalui proses gridding. Setelah peta residual diperoleh, dilakukan perhitungan peta hasil kalkulasi regresi linier dengan peta residual sehingga mendapatkan peta struktur domain kedalaman yang sesuai dengan kondisi sesungguhnya.



Gambar 11. Peta Residual Kedalaman Terhadap Tops Sumur Lapisan Transisi.

\section{HASIL DAN PEMBAHASAN}

\section{Analisis Struktur}

Analisis struktur bertujuan untuk menemukan struktur jebakan hidrokarbon baru pada ketiga lapisan, yaitu Lapisan Transisi, Upper Menggala, dan Lower Menggala. Pada analisis struktur ini, dilakukan analisis zona-zona yang menarik berdasarkan keberadaan struktur jebakan seperti antiklin atau sinklin. Pada studi sebelumnya, telah dilakukan eksplorasi dan pemetaan struktur pada wilayah reservoar primer (Upper Sihapas dan Lower Sihapas), studi itu menghasilkan beberapa struktur besar pada Lapangan Kaprasida, yaitu struktur TG1, TG2, dan TG3. Dari studi sebelumnya, dapat dilihat bahwa dominan struktur yang berada pada lapangan ini berupa struktur antiklin. Berikut ini adalah peta struktur domain kedalaman ketiga lapisan secara berturut-turut. 


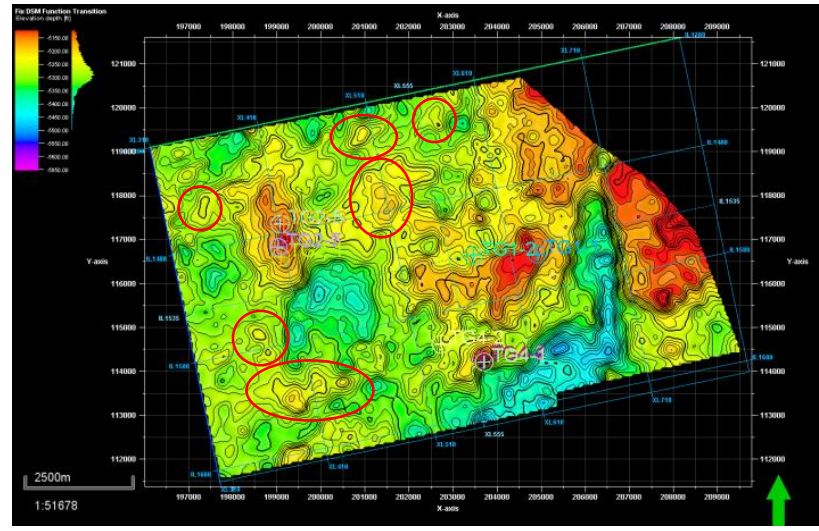

Gambar 12. Peta Struktur Domain Kedalaman Lapisan Transisi.

Gambar 12 merupakan peta struktur domain kedalaman lapisan Transisi, terlihat pada gambar tersebut terdapat beberapa struktur antiklin baru selain struktur TG1, TG2, dan TG4. Struktur baru tersebut ditandai dengan lingkaran merah, yaitu sebanyak enam struktur antiklin. Zona struktur baru pada lapisan Transisi meliputi wilayah Utara TG1, Barat TG2, Timur TG2, Selatan TG2, dan Barat TG4.

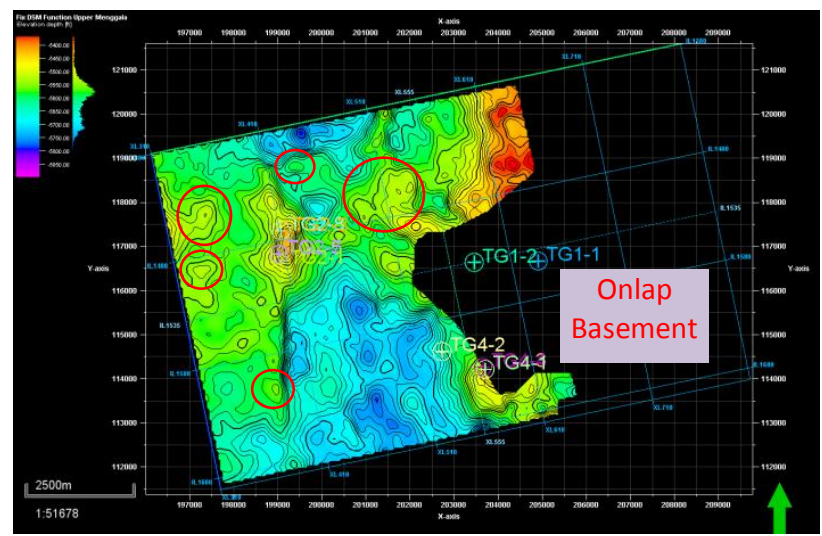

Gambar 13. Peta Struktur Domain Kedalaman Lapisan Upper Menggala.

Gambar 13 merupakan peta struktur domain kedalaman lapisan Transisi, terlihat pada gambar tersebut terdapat beberapa struktur antiklin baru selain struktur TG1, TG2, dan TG4. Struktur baru tersebut ditandai dengan lingkaran merah, yaitu sebanyak lima struktur antiklin. Zona struktur baru pada lapisan Transisi meliputi wilayah Utara TG1, Barat TG2, Timur TG2, Selatan TG2, dan Utara TG2.



Gambar 14. Peta Struktur Domain Kedalaman Lapisan Lower Menggala.

Gambar 14 merupakan peta struktur domain kedalaman lapisan Transisi, terlihat pada gambar tersebut terdapat beberapa struktur antiklin baru selain struktur TG1, TG2, dan TG4. Struktur baru tersebut ditandai dengan lingkaran merah, yaitu sebanyak lima struktur antiklin. Zona struktur baru pada lapisan Transisi meliputi wilayah utara TG1, barat TG2, timur TG2, selatan TG2, dan utara TG2.

\section{PENUTUP}

\section{Kesimpulan}

Kesimpulan yang didapat dari penelitian ini antara lain.

1. Terdapat enam struktur jebakan hidrokarbon pada Lapisan Transisi, yaitu pada zona Btara TG1, barat TG2, Timur TG2, Selatan TG2, dan Barat TG4.

2. Terdapat lima struktur jebakan hidrokarbon pada Lapisan Transisi, yaitu pada zona Utara TG1, Barat TG2, Timur TG2, Selatan TG2, dan Utara TG2.

3. Terdapat lima struktur jebakan hidrokarbon pada Lapisan Transisi, yaitu pada zona Utara TG1, Barat TG2, Timur TG2, Selatan TG2, dan Utara TG2.

4. Dengan ditemukannya beberapa struktur yang diduga sebagai jebakan hidrokarbon baru, memperlihatkan bahwa pada Lapangan Kaprasida, khususnya reservoar sekunder, masih memiliki peluang sebagai sumber hidrokarbon yang layak diproduksi untuk pengembangan lapangan ini. 


\section{Saran}

Saran yang dapat diberikan berdasarkan hasil dan kesimpulan untuk membangun hipotesishipotesis selanjutnya antara lain.

1. Untuk mendapatkan tingkat keyakinan tinggi terhadap struktur tersebut, layaknya dilakukan studi lanjutan mengenai karakterisasi reservoar tersebut melalui proses inversi atau analisis atribut seismik.

2. Untuk mendapatkan nilai cadangan, layaknya dilakukan studi lanjutan mengenai analisis perhitungan cadangan hidrokarbon dengan metode volumetrik atau yang lainnya.

\section{Ucapan Terima Kasih}

Penulis mengucapkan terima kasih kepada para dosen pembimbing Bapak Ayi Syaeful Bahri, Mas Juan Pandu, dan Mas Dhimas Arief atas ide penulisan dan pengarahannya selama proses penelitian hingga penulisan.

\section{DAFTAR PUSTAKA}

Agun, Satryo, 2007. Bab II: Teori Dasar Struktur Sesar dan Interpretasi pada Data Seismik Refleksi 3D. Laporan Tugas Akhir. Institut Teknologi Bandung.

Alfian, Rino, 2007. Studi Analisa Sekatan Sesar dalam Menentukan Aliran Injeksi pada Lapangan Kotabatak, Cekungan Sumatera Tengah. Laporan Tugas Akhir. Bandung: Institut Teknologi Bandung.

Brown, Alistair R., 2010. Interpretation of ThreeDimensional Seismic Data. Dallas: AAPG dan SEG.

Departemen Geoscience Energi Mega Persada, 2009. Geologi Regional Cekungan Sumatera Tengah. Jakarta: EMP

Sukmono, Sigit, 2005. Seismic Methods for Field Exploration \& Developments. Volume 1 and 2. Bandung: ITB.

Sukmono, Sigit, 2007. Fundamental of Seismic Interpretation. Dept. of Geophysical Engineering. Bandung: ITB. 